\title{
LA LEY NACIONAL SOBRE VIOLENCIA CONTRA LAS MUJERES Y SU TRATAMIENTO EN LA PRENSA ARGENTINA: ENTRE LO POLÍTICAMENTE CORRECTO Y LA ELUSIÓN
}

Ana Soledad Gil ${ }^{1}$

Resumen: El problema de la violencia contra las mujeres es mundial y complejo. Argentina sancionó en el año 2009 la ley $\mathrm{N}^{\circ} 26.485$ que busca prevenir, sancionar $\mathrm{y}$ erradicar la violencia de género en los ámbitos públicos y privados. En este trabajo, analizamos los sentidos construidos por la prensa argentina sobre la norma. Entendemos que los discursos que expresan los medios son fundamentales para comprender la problemática y poder erradicar el flagelo. No obstante, el artículo presenta, entre sus hallazgos principales, posiciones que van desde lo políticamente correcto hasta la elusión. El estudio toma la perspectiva de género y las herramientas del análisis del discurso social y crítico.
Palabras Clave: Violencia contra las mujeres. Ley Nacional 26.485. Prensa argentina. Construcciones de sentido

\begin{abstract}
The main issue of violence against women is global and complex. Argentina enacted in 2009 the Act No. 26,485 with the goal to prevent, punish and eradicate gender violence. In this paper, we analyze the Argentine media view about the construction of this Act. We understand that the media opinion is fundamental to understand this issue and to be able to eradicate it. However, the article presents, among its main goal, positions ranging from the politically correct to the circumvention. We have studied the gender perspective and the
\end{abstract}

\footnotetext{
${ }^{1}$ Actualmente, becaria postdoctoral de CONICET Mendoza, Argentina. Licenciada en Comunicación Social y Doctora en Ciencias Sociales por la Facultad de Ciencias Políticas y Sociales de la Universidad Nacional de Cuyo, Mendoza, Argentina. Diplomada en Comunicación y Género por la Asociación Comunicar Igualdad y la Universidad Nacional de San Martín, Buenos Aires, Argentina. Docente adscripta de la materia Filosofía y Pensamiento Feministas de la carrera de Comunicación social de la Facultad de Ciencias Políticas y Sociales de la Universidad Nacional de Cuyo, Mendoza, Argentina. Integrante de la RED PAR (Periodistas de Argentina en Red por una Comunicación no Sexista).
} 


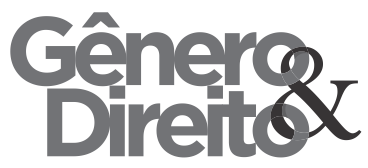

Periódico do Núcleo de Estudos e Pesquisas sobre Gênero e Direito Centro de Ciências Jurídicas - Universidade Federal da Paraíba

V. 6 - $\mathrm{N}^{\circ} 02$ - Ano 2017

ISSN | 2179-7137 | http://periodicos.ufpb.br/ojs2/index.php/ged/index analysis about social and critical discourse.

Keywords: Violence against women. National Act 26.485. Argentine Media. Social discourse

\section{INTRODUCCIÓN}

El presente artículo se desprende de una investigación de mayor envergadura en la que se analizaron los sentidos de la violencia de género en la prensa argentina. Dada la centralidad que tiene en el tema la ley nacional 26485 de "Protección integral para prevenir, sancionar y erradicar la violencia contra las mujeres en los ámbitos en que desarrollen sus relaciones interpersonales", $\quad$ sancionada $\quad \mathrm{y}$ promulgada en el año 2009, aquí nos proponemos dar a conocer los hallazgos obtenidos en relación a los sentidos construidos sobre la misma por los diarios representativos, Clarín y La Nación.

Entendemos que la violencia de género es un flagelo mundial complejo que atiende a cuestiones estructurales que

\footnotetext{
2 Esta asociación tiene relevancia nacional en cuanto al tema que nos convoca ya que además de trabajar en la prevención y concientización de la
}

115

dificultan su erradicación. Para la Organización Mundial de la Salud, la violencia contra las mujeres por el sólo hecho de serlo es una pandemia. En Argentina, las estadísticas demuestran que las situaciones de violencia de género y su expresión extrema, los femicidios, han aumentado y se han recrudecido en los últimos años. Según la organización civil La Casa del Encuentro, una mujer muere cada 30 horas en nuestro país como consecuencia de la violencia patriarcal. Entre el 1 de enero y el 31 de octubre de 2016, se contaron 230 femicidios y femicidios vinculados de mujeres y niñas. 95 de ellos fueron perpetrados por “esposos, parejas, novios", 86 mujeres tenían entre 19 y 30 años, la mayoría fue asesinada en su propia casa, entre otros datos. $^{2}$

Desde la sanción de la mencionada ley 26485, el tema de la violencia de género ganó un lugar destacado en los medios en general y en la prensa argentina en particular (Autor, 2016). Sabemos que los medios de comunicación son importantes actores

violencia de género, brinda -aunque no oficialmente- datos estadísticos sobre femicidios. http://www.lacasadelencuentro.org/. 
culturales, pero también económicos y políticos. En sus construcciones de sentido y en los discursos que expresan se encuentran en tensión estos intereses y cuando abordan temas de género como la violencia contra las mujeres, tal tensión también se manifiesta. Por ello, frente a la gran visibilización que tiene el tema en los medios se indaga acerca de los sentidos que adquirió la ley de violencia en los principales diarios de alcance nacional del país, dado que se trata de un hito para comprender la problemática y nos permite vislumbrar las valoraciones y lo decible en y para cada uno. Para alcanzar dichos objetivos y responder las inquietudes utilizamos las herramientas del análisis del discurso crítico y social.

Los principales hallazgos sostienen que cada diario presentó un posicionamiento diferencial frente a la sanción de la ley nacional 26.485 de Prevención, Sanción y Erradicación de la violencia contra las mujeres. Mientras Clarín, fiel a un lector modelo identificado con la clase media argentina que comparte un sentido común en el que el respeto por las leyes, las normas y los derechos son núcleos importantes, construye sentido positivo sobre la norma dentro de los umbrales legalistas del asunto, mostrándose políticamente correcto; $L a$ Nación, arremete contra la misma dado su articulado en relación a las decisiones reproductivas de las mujeres y la posibilidad, según construyó el medio a través de fuentes específicas (legisladores/as ultracatólicos/as, varones), de que pudiese abrir el debate sobre la despenalización y legalización de la interrupción voluntaria del embarazo en Argentina.

\section{VIOLENCIA DE GÉNERO Y FEMICIDIOS}

El problema de la violencia contra las mujeres, está ceñido de complejidades que urge revisar y dilucidar porque en él se va la vida de las mujeres a nivel mundial en una escalada que no se puede soslayar. En tal sentido, se presenta como una pandemia mundial al compás de la globalización.

Para ir adentrándonos en esa complejidad, Lagarde afirma que la violencia contra las mujeres es grave y multifactorial y la enmarca en una 
articulación sinérgica entre un conjunto de determinaciones que se basan en la dominación. Es así que, articulada con el clasismo, el racismo, la discriminación etaria y étnica se convierte en una realidad para todas las mujeres, en el mundo entero. En grados diversos, todas las mujeres vivimos formas de violencia de género en el curso de nuestras vidas. Todas, vivimos formas de violación de nuestros derechos humanos derivadas de la subalternidad social y la subordinación política de género.

Así es que para la estudiosa mexicana la violencia de género es parte constitutiva de la opresión de las mujeres que aparece como el "máximo mecanismo" de reproducción de esa opresión (apud Lagarde, 2012:199) y la define como

la violencia misógina contra las mujeres, por ser mujeres ubicadas en relaciones de desigualdad de género: opresión, exclusión, subordinación, discriminación, explotación y marginación. Las mujeres son víctimas de amenazas, agresiones, maltrato, lesiones y daños misóginos. Los tipos de violencia son: física, psicológica, sexual, económica y patrimonial y las

${ }^{3}$ Lagarde destaca en este punto que sigue a Celia Amorós (1997:358) quien ubica al patriarcado como "siempre incardinado en un entramado social e histórico concreto donde se entrecruza con muchas variables relevantes como la clase, la raza,
117

modalidades de la violencia de género son: familiar, laboral $\mathrm{y}$ educativa, en la comunidad, institucional y feminicida (Lagarde, 2008:235).

Para la académica mexicana, la violencia de género contra las mujeres es estructural porque la organización de la vida social es patriarcal. ${ }^{3}$ Se trata de una sólida construcción de relaciones, prácticas e instituciones sociales en las que está incluido el Estado, que generan, preservan y reproducen poderes de los varones sobre las mujeres.

Sobre los femicidios, que son la expresión extrema de un contiuum de violencias, cabe especificar que distintas construcciones teóricas coinciden en que femicidio/feminicidio es un "concepto político, posicionado colectivamente por organizaciones de mujeres para denunciar la inequidad entre mujeres y varones -solo explicable desde una perspectiva de género-, la impunidad y la ineficacia de los Estados para terminar con ella" (Barcaglione, 2010:148). Lagarde (2008) profundiza estas ideas y conceptos al

etc." y aclara que si bien es un concepto que debe ser contextualizado, nos permite dar cuenta de la dominación que ejerce el conjunto varones sobre las mujeres. 
hablar de violencia femicida como la culminación de múltiples formas de violencia de género contra las mujeres que atentan contra sus derechos humanos y las conducen a variadas formas de muerte violenta toleradas por la sociedad y el Estado y se produce por la organización social genérica jerárquica, de supremacía e inferioridad, que crea desigualdad entre mujeres y varones.

\section{LA LEY 26.485 "VIOLENCIA CONTRA LA MUJER. PREVENCIÓN, SANCIÓN Y ERRADICACIÓN".}

En cumplimiento de las convenciones y tratados internacionales ratificados y, en consonancia con la lucha de los movimientos de mujeres/feministas, el 11 de marzo de 2009 fue sancionada y el 1 de abril de ese mismo año, promulgada en Argentina la Ley Nacional $\mathrm{N}^{\circ} 26.485$ "Violencia Contra La Mujer. Prevención, Sanción y Erradicación”. La norma fue

4 La Convención sobre la Eliminación de todas las Formas de Discriminación Contra la Mujer, en el marco de la década de la mujer 1975- 1985, fue declarada en 1979. No se trata del primer ni único tratado internacional de protección de derechos de las mujeres en el marco de las Naciones Unidas,
118

celebrada por distintos organismos internacionales dada su mirada integral sobre el problema. De hecho, en 2010, el Comité de seguimiento de la CEDAW, cuando examinó el informe periódico de Argentina, saludó gratamente algunos avances, entre los que se encontraba la sanción de la Ley 26.485 (apud Chaher, 2012). ${ }^{4}$

El cuerpo normativo, en el título primero sobre disposiciones generales, aclara en el artículo $n^{\circ} 4$ que la violencia contra las mujeres queda definida como toda conducta, acción u omisión, que, de manera directa o indirecta, tanto en el ámbito público como en el privado, basada en una relación desigual de poder, afecte su vida, libertad, dignidad, integridad física, psicológica, sexual, económica o patrimonial, como así también su seguridad personal. Quedan comprendidas las perpetradas desde el Estado o por sus agentes. Se considera violencia indirecta, a los efectos de la presente ley, toda conducta, acción u omisión, disposición, criterio o práctica discriminatoria que ponga a la mujer en desventaja con respecto al varón.

Asimismo, nos interesa rescatar que, en el artículo 5, quedan especialmente

pero sí el más importante. De hecho, se la llama "La Carta Internacional de los Derechos Humanos de las Mujeres". CEDAW, por su sigla en inglés: The Convention on the Elimination of All Forms of Discrimination against Women. 
comprendidos cinco tipos de violencias contra las mujeres: física, sicológica, sexual, económica y patrimonial y simbólica. A esta última, la define como

la que, a través de patrones estereotipados, mensajes, valores, íconos o signos transmita y reproduzca dominación, desigualdad y discriminación en las relaciones sociales, naturalizando la subordinación de la mujer en la sociedad.

También, el artículo 6 es fundamental dado que en él se establecen las seis modalidades que adoptan las violencias de género contra las mujeres: doméstica, institucional, laboral, contra la libertad reproductiva, violencia obstétrica y violencia mediática. A esta última la define como

aquella publicación o difusión de mensajes e imágenes estereotipados a través de cualquier medio masivo de comunicación, que de manera directa o indirecta promueva la explotación de mujeres o sus imágenes, injurie, difame, discrimine, deshonre, humille o atente contra la dignidad de las mujeres, como así también la utilización de mujeres, adolescentes y niñas en mensajes e imágenes pornográficas, legitimando la desigualdad de trato o construya patrones socioculturales reproductores de la desigualdad o generadores de violencia contra las mujeres.
Relacionado con los medios de comunicación y la perspectiva de género, entendemos que se trata de una norma de protección que apunta al cambio cultural. La dimensión simbólica incide, de manera lenta y por momentos indirecta, en la moral, las costumbres, el sentido común compartido y el substrato prejuicioso del que emanan las violencias y la discriminación contra las mujeres. Es por eso que la reforma de las leyes y la introducción de un lenguaje más preciso, adecuado y la expansión permanente de un sistema de nombres para cada situación, es un procedimiento imprescindible $\mathrm{y}$ fundamental. Esta ley y las dimensiones de sentido que instala, al referirse por primera vez a la violencia simbólica y la violencia mediática como una de sus modalidades más eficaces, marcan un hito en la problematización del sexismo en los medios de comunicación.

\section{DE MEDIOS DE COMUNICACIÓN. LOS DIARIOS CLARÍN Y LA NACIÓN}

La relación entre los medios, sus representaciones y sus construcciones discursivas y las mujeres ha sido 
históricamente compleja. Entendemos que dicha relación se configura en un contexto de desigualdades que anteceden a la comunicacional actual y que los medios no son los causantes de la discriminación de las mujeres en la sociedad, no obstante, los derechos de las mujeres se ponen en juego en el orden mediático y periodístico. En este sentido, los medios de comunicación pueden mantener el orden jerárquico y desigual de género o pueden contribuir a transformarlo en favor de la equidad.

De tal manera, se vuelve necesario pensar la comunicación como parte de procesos políticos, sociales y culturales en los que hay múltiples actores, conflictos y situaciones. En toda sociedad existen experiencias históricamente compartidas que constituyen la base del sentido común y de las prácticas cotidianas. De este modo, en un contexto histórico específico, una sociedad comparte una serie de presupuestos, sentidos y prácticas que, a la vez, son la base de disputas de otros sentidos y prácticas. Raymond Williams (1980) nos recuerda que la cultura es un fenómeno fundamental para comprender las relaciones de desigualdad en una sociedad, y es aquí donde los medios de comunicación detentan un importante rol en la disputa por los sentidos, ideas, visiones de mundo que adquiere una sociedad, en un determinado momento histórico.

En otras palabras, en este trabajo entendemos que los medios cumplen un papel protagónico en la conformación de sentidos sociales y/o en términos gramscianos, de un sentido común. Los medios ocupan un lugar central en cuanto a los modos en que una sociedad se ve y se piensa a sí misma, es decir, en cuanto a los modos en que una sociedad construye sentidos (raciales, religiosas, generacionales, institucionales, políticas, de clase, de género, laborales, etc.).

Asimismo, los consideramos en su dimensión económica. Tal como indica Denis De Moraes (2013) son la celebración de la vida para el mercado, consumismo, individualismo, "la existencia subordinada al mantra de la rentabilidad", pero también comprendemos que los medios son actores políticos concretos, esto es que, además de sus objetivos periodísticos, tienen la 


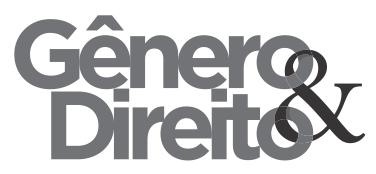

capacidad de afectar procesos, influenciando a la sociedad.

Esta característica no es sólo por su posibilidad privilegiada de interpretar la realidad social y formar corrientes de opinión masivas, sino también por su capacidad de legitimar o deslegitimar ciertos relatos sociales; y más aún aquellos que intentan imponerse desde las esferas del poder político (Borrelli, 2013).

En tal sentido, hay coincidencia para decir que los enfoques mediáticos son androcéntricos: el varón (blanco, heterosexual, propietario) es la medida de todas las cosas, el centro desde el cual se mira y se construye sentido, mientras que las mujeres ocupan el lugar de "otra" de la cual se habla, ubicándolas en la inferioridad (Autor, 2011). La crítica al androcentrismo implica visibilizar que se trata de un punto de vista situado desde el cual se construyen, en el caso de los medios, las informaciones y representaciones mediáticas. Incorporar la mirada de género en los medios de comunicación alude a desnaturalizar esas visiones de mundo androcéntricas, presentadas como neutrales, objetivas $\mathrm{y}$ universales que, históricamente han
Céco do Núcleo de Estudos e Pesquisas sobre Gênero e Direito Centro de Ciências Jurídicas - Universidade Federal da Paraíba V. 6 - $\mathrm{N}^{\circ} 02$ - Ano 2017

reproducido desigualdades entre mujeres y varones.

Finalmente, en este apartado cabe consignar algunas características relevantes de los dos diarios argentinos elegidos para esta pesquisa.

El diario Clarín, fundado por Roberto J. Noble lanzó su primer número al público el 28 de agosto de 1945, momento en el que debió hacerse un espacio en un mercado periodístico en el que sobresalían La Prensa, La Nación y El Mundo. El medio tuvo una carrera ascendente desde su primer número, así fue que, a fines de los años '60, ya era uno de los primeros diarios en el ranking de ventas nacionales. También se había posicionado como un referente clave de la clase media de los principales centros urbanos de la Argentina. Es el principal diario argentino y el de mayor circulación en el mundo de habla hispana desde el año 1985, tal como reza la cronología publicada en su propia página web http://www.grupoclarin.com.ar.

El tradicional diario La Nación fue fundado por Bartolomé Mitre, el 4 de enero de 1870, bajo el lema "será una tribuna de doctrina". Mitre era periodista, 
político, historiador, legislador, diplomático y fue presidente de Argentina entre 1862 y 1868 , en el marco de lo que se llamó el período de la "organización nacional". Mitre fue un exponente del pensamiento liberal en lo económico y conservador en lo social. El principal lectorado de este diario se ubica entre los sectores de mayor poder adquisitivo del país entre los que se cuentan militares retirados en ejercicio de sus funciones durante la dictadura militar. ${ }^{5}$ Resulta interesante destacar que, en diciembre del '95, La Nación fue el primer diario de circulación nacional en incorporarse a Internet con el dominio www.lanacion.com.ar.

\section{APUNTES METODOLÓGICOS: EL ANÁLISIS SOCIAL Y CRÍTICO DEL DISCURSO}

Como ha sido expuesto, en relación al rol destacado de los medios de comunicación en los procesos culturales, en la expresión de determinados valores y visiones de mundo, en la construcción de hegemonía y el establecimiento de un sentido común compartido y, también, al estar insertos en la disputa por los sentidos sociales en clara posición de privilegio (apud Van Dijk, 2003), en tanto ocupan espacios y posiciones de poder, el método del análisis del discurso se presenta pertinente para el desarrollo del presente trabajo.

La perspectiva aquí adoptada considera al lenguaje en cuanto forma de práctica social, vinculada a sus condiciones sociales de producción y a su marco de producción institucional, ideológica cultural e histórico-coyuntural y se centra en los modos en los que la dominación política y social se reproduce a través de los textos, en los modos en que se disputa y dirime la lucha por los sentidos sociales. Se trata, en definitiva, de asumir una posición más cuestionadora de la realidad circundante, principalmente, cuando lo que se busca es dilucidar cómo los discursos sociales reproducen el abuso de poder, la dominación o la desigualdad social.

5 Referimos al último golpe cívico-militar que sufrió Argentina en 1976. 
Los criterios que guían nuestros análisis tienen como centro la propuesta bajtiniana que concibe a los discursos como prácticas $\mathrm{y}$, al mismo tiempo, como hechos sociales. Es decir, el discurso tiene una materialidad específica desde esta perspectiva. Asimismo, un discurso siempre está orientado y conlleva las marcas de quien habla, de género, de clase, raza y de conflicto. Desde este marco, la categoría de signo es central dado que en él está la ideología de quien lo usa y transmite. Según Valentín Voloshinov, la palabra es un "signo ideológico estructurado socialmente" y llega a ser “arena de lucha de clases" (2009:47). En tal sentido, la categoría de "multiacentualidad" del signo es una importante guía en este trabajo que busca dilucidar el sentido adjudicado por la prensa argentina a la ley 26.485 de violencia contra las mujeres. En palabras de Voloshinov, los sectores dominantes buscan "adjudicar al signo ideológico un carácter "eterno" por encima de las clases sociales, pretende apagar y reducir al interior la lucha de valoraciones sociales que se verifican en él, trata de convertirlo en un signo monoacentual" (2009:48).
En la misma línea, la propuesta de Marc Angenot suma categorías para poder analizar lo planteado. Este autor propone la existencia de una hegemonía discursiva pero que admite la presencia de fisuras o deslizamientos discursivos a través de los cuales se mantiene una lucha por imponer nuevos o viejos paradigmas. Desde su perspectiva, se trata un "decible global" más allá del cual no es posible, por anacronismo, percibir lo todavía no dicho pero que, justamente, marca la existencia de "un no dicho" en ese orden discursivo. Sintéticamente, para Angenot (2010), el discurso social tiene tres funciones: representa al mundo, produce a la sociedad y sus identidades, construye lo real (función óntica); axiológico: valoriza, clasifica y legitima (función axiológica) y sugiere, hace actuar, dicta reglas (función pragmática).

Para seguir, las herramientas aportadas por el semiólogo Eliseo Verón para analizar los discursos en una sociedad a partir de las huellas que los procesos de producción inscriben en ellos, resultan pertinentes. Para Verón (1997), el discurso hace referencia a un conjunto de imágenes producida colectivamente y que determina 
una visión de mundo, el sentido sólo es observable en textos discursivos y el texto es cualquier cosa capaz de generar lecturas e interpretaciones. ${ }^{6}$ En suma, un discurso es una ubicación del sentido en el espacio y en el tiempo (apud Verón, 2004:49).

Desde el punto de vista veroniano, en todo discurso político hay un "enunciador" que es una modelización abstracta que permite construir la imagen de quien habla y en toda enunciación política hay un adversario. ${ }^{7}$ Cuando Verón (1987) habla de tres destinatarios para un enunciador, plantea que todo enunciado construye un otro positivo y un otro negativo, que conforma la relación entre enunciador y destinatario. $\mathrm{El}$ destinatario positivo participa de las mismas ideas que el enunciador, adhiere a los mismos valores y persigue los mismos objetivos. Lo llama prodestinatario y se corresponde con el colectivo de identificación, el nosotros inclusivo. El destinatario negativo está excluido de esta

\footnotetext{
${ }^{6}$ No solamente hay textos orales y escritos, como una conversación entre dos amigos, un diálogo en el chat o artículos de opinión en el periódico. También son textos los anuncios publicitarios o las películas. Cualquier cosa susceptible de ser leída o interpretada puede considerarse texto; y como tal constituye la manifestación de uno o más discursos (Verón, 1997).
}

identificación, lo llama contradestinatario y descansa sobre la hipótesis de una inversión de la creencia. Ahora bien, tal como plantea el autor, el análisis de los discursos revela un tercer tipo de destinatario que aparece como por "fuera del juego", los/as indecisos/as a quienes hay que persuadir. A esta tercera posición la llama paradestinatario y se basa en la hipótesis de suspensión de la creencia. A este destinatario el discurso buscará convencer, persuadir.

En síntesis, Verón (1987) marca que todo discurso busca un refuerzo del prodestinatario, la polémica con el contradestinatario y la persuasión del paradestinatario.

Finalmente, restan sumar en este apartado las categorías acuñadas por Raymond Williams al referirse a la complejidad de la cultura. Distingue tres elementos que se interrelacionan en todo proceso cultural: lo dominante, lo residual y lo emergente. ${ }^{8}$

\footnotetext{
${ }^{7} \mathrm{Si}$ bien el mismo Verón extrapola en sus estudios estas categorías al discurso mediático, cabe aclarar que para este trabajo resultan además pertinentes dado que entendemos al discurso periodístico como político y a los diarios como actores políticos.

${ }^{8}$ En líneas generales, para Williams lo dominante es lo hegemónico; lo residual ha sido formado efectivamente en el pasado, pero todavía se halla en actividad dentro del proceso cultural, no sólo como
} 
PRINCIPALES HALLAZGOS

Clarín

Como vimos líneas arriba, Argentina sancionó en abril de 2009, la ley 26485 de "Protección integral para prevenir, sancionar y erradicar la violencia contra las mujeres en los ámbitos en que desarrollen sus relaciones interpersonales".

Concretamente, el diario Clarín publicó tres titulares referidos a la norma y su sanción: el 7 de marzo de 2009, aún sin contar con sanción definitiva, el medio alude a la misma con motivo del Día Internacional de la Mujer. Con el título "La violencia de género mata", 9 en el matutino se vislumbra, desde la concepción de Voloshinov, un deslizamiento de signos, es decir, el abandono de 'crimen pasional' y el ingreso de 'violencia de género'. Al decir de Williams, nos encontramos con un elemento emergente en el proceso cultural, específicamente, en relación a la violencia

un elemento del pasado, sino como un efectivo elemento del presente; y lo emergente son aquellos nuevos significados y valores, nuevas prácticas, nuevas relaciones.
125

contra las mujeres. La nota de mediana extensión presenta una fotografía en la que aparecen Eleonor Faur por ONU, la senadora Marita Perceval y Luis Alejandro Otero de la Red PAR, por una comunicación no sexista. Las fuentes utilizadas en la pieza responden a las declaraciones de estas personas mencionadas y suma datos del Banco Mundial sobre el flagelo de la violencia contra las mujeres. En palabras de la senadora Perceval se insta a sancionar la norma, en las de Faur a considerar el problema como concerniente a los Derechos Humanos y, sintéticamente, a visibilizar y abordar el tema en un día como el Día Internacional de la Mujer. En este contexto, la construcción discursiva propia del medio "este es un delito que se expande como un virus persistente y tiene al silencio como cómplice en las familias y a nivel institucional" insta a, por un lado, catalogar de "delito" a la violencia ejercida contra las mujeres por el sólo hecho de ser mujeres. Esta es la primera acentualidad adjudicada al signo, siguiendo a

9 http://edant.clarin.com/suplementos/mujer/2009/0 3/07/m-01871965.htm 
Voloshinov, que se detecta. Por otro lado, también, reclama derribar el silencio y apela a las "familias" y a las "instituciones" como responsables.

El 12 de marzo de 2009, día posterior a la sanción de la ley, el título de Clarín fue "La cámara de diputados aprobó ayer la nueva norma. Por ley, buscan prevenir la violencia contra las mujeres desde la escuela". ${ }^{10}$ Se trató de una nota de mediana extensión en la que se daba cuenta de los distintos tipos de violencia de género, entre otros puntos de la ley. Fue publicada en la sección sociedad y tomó como fuentes principales al mismo texto de la ley, la voz de diputadas promotoras de la misma y la opinión especializada de INADI (Instituto Nacional contra la Discriminación, la Xenofobia y el Racismo) y de Amnistía Internacional. Al tratarse de una normativa de fondo, tal como expresa la noticia, no se detectan valoraciones, en el sentido de Angenot, acerca de la función axiológica de los discursos. En todo caso, se presenta como una pieza "políticamente correcta" que apela a la lengua legítima reconocida

10

http://edant.clarin.com/diario/2009/03/12/sociedad $\underline{\text { s-01875315.htm }}$ por todos/as y desde allí explaya su función óntica al contribuir a la construcción de la realidad sobre el problema de la violencia de género contra las mujeres.

Finalmente, el 23 de marzo se destaca en Clarín una nota de opinión de Monique Thiteux Altschul, Directora Ejecutiva de la Fundación Mujeres En Igualdad, titulada "Una ley que reclama un cambio de cultura". "I En ella, la función axiológica puede verse cuando la autora sostiene que es "un gran avance la ley" para prevenir y sancionar la violencia contra las mujeres, pero exige un fuerte compromiso del Estado y la sociedad toda. En el texto presenta muchas preguntas como, por ejemplo, "los fondos adjudicados ¿se revertirán en políticas públicas que alcancen a todo el país, que articulen eficiente y transparentemente recursos? ¿Se crearán nuevos hogares para mujeres golpeadas, equipos de asistencia psicológica y legal? Y la justicia, ¿podrá hacer cumplir las exclusiones del hogar, el cese de los actos de intimidación, la prohibición de que el

11

http://edant.clarin.com/diario/2009/03/23/opinion/ o-01882694.htm 
presunto agresor compre armas? ¿Habrá más y mejor patrocinio jurídico gratuito?" Ante estas incertidumbres, la nota apela al compromiso del Estado y de la sociedad civil para lograr un cambio cultural que logre erradicar la violencia contra las mujeres. Claramente, se trata de una voz especializada en el tema, con conocimiento de las circunstancias reales y complejas que atañen a la violencia de género y en este sentido, la función predominante es la pragmática, es decir, hay un sugerir hacer que se dirige al Estado como principal destinatario secundado por la sociedad civil en su conjunto.

En síntesis, el tratamiento que este diario realiza sobre la ley 26485 y su sanción, es políticamente correcto en un estado de derechos. Es decir, hay una valoración positiva sobre la existencia de la norma en tanto función axiológica y una apelación al hacer para las instituciones y el Estado en su función pragmática. La doxa, en tanto tópica que apela al sentido común, se ubica en los umbrales de un cierto estado de cosas en el que las normas y leyes deben ser cumplidas. Desde este lugar, el medio apela a distintas fuentes que se presentan como voces autorizadas: organismos internacionales y nacionales y personas con un lugar destacado y especializado en relación al problema. En este corpus, hay un prodestinatario que se identifica con la idea de cumplir con las leyes y exigirle al Estado mayor compromiso con ello. El contradestinatario no surge como adversario concreto, sin embargo, se trata del Estado y sus instituciones "cómplices" del silencio y del flagelo en sí. Aún luego de la sanción y promulgación de la ley de violencia contra las mujeres, se apuesta en esa dirección. Es decir, en sentido bajtiano el discurso se orienta hacia el aparato estatal y sus responsables.

\section{La Nación}

El tratamiento que el diario de alcance nacional La Nación realiza sobre la sanción de la ley 26.485 es llamativo. Para empezar, el medio señala a la ley como "polémica" porque, según se argumenta, habilita la práctica del aborto que, en Argentina, está penalizada con excepción de tres causales según el Código Penal: violación, peligro de vida de la 
mujer gestante, malformaciones del feto. En este marco, el diario publicó como noticia central en la sección Información general, el 12 de marzo de 2009, una pieza titulada "Polémica por una ley que protege a la mujer". ${ }^{12} \mathrm{El}$ cuerpo de la nota dice que "el debate sobre la posibilidad de que esta ley abra una puerta a la despenalización del aborto impidió que el proyecto fuera aprobado por unanimidad", como así también que "la inclusión del derecho de la mujer a decidir sobre la vida reproductiva, número de embarazos y cuándo tenerlos" y "las intervenciones favorables al aborto de distintas diputadas encendieron la discusión". Una de las fuentes citadas es Cinthia Hotton (Pro-Capital) quien pidió "no mezclar los derechos de las mujeres con otro debate", en el que se defiende "el derecho a la vida".

En la misma línea de sentido, el medio publicó el 4 de abril de ese año, una nota de opinión con el título "Ley de protección de la mujer" firmada por Néstor Pedro Sagüés, profesor titular de Derecho Constitucional, UBA y UCA. ${ }^{13}$

\footnotetext{
12 http://www.lanacion.com.ar/1107786-polemicapor-una-ley-que-protege-a-la-mujer
}

128

Es una pieza muy extensa en la que quien escribe se asegura dejar en claro que la ley no habilita la discusión acerca de la legalización y despenalización del aborto porque eso sería inconstitucional: "hay al menos tres normas específicas, de nivel constitucional, que tutelan a la persona por nacer, tal vez el ser más vulnerable y, por ende, el más digno y necesitado de custodia"; "los derechos reproductivos de la mujer y del hombre tienen, como regla, el tope del derecho a la vida del sujeto por nacer"; "cabe tener presente algo importante pero, paradójicamente, no siempre recordado: que la persona por nacer también tiene derechos humanos, empezando por el de su vida". El enfoque es androcéntrico, sexista y el discurso está orientado a reforzar la idea de que, en última instancia, no es tan importante el derecho de las mujeres a vivir una libre de todo tipo de violencias. En este caso, la valoración positiva está dada sobre "la persona por nacer" y no sobre las mujeres como ciudadanas con derechos humanos. El sentido de la ley 26485 queda completamente obturado bajo este

\footnotetext{
13 http://www.lanacion.com.ar/1115191-ley-deproteccion-de-la-mujer
} 
tratamiento en el que subyace una proclama por mantener el statu quo imperante. En sintonía, en otra pieza de opinión del 19 de abril de 2009, se lee "las feministas (...) quieren mantener la exclusividad en el asunto, ser las dueñas únicas de los golpes y las vejaciones", al hacer alusión a que, supuestamente para este medio, la violencia no tiene género quitándole especificidad al problema de la violencia contra las mujeres y los femicidios, provocando un deslizamiento de sentido peligroso, en tanto obtura la mirada sobre el flagelo.

En todo este abordaje en ningún momento asoma el signo 'violencia de género', mucho menos 'femicidio', de hecho el diario habla de 'la mujer' y del 'hombre' de manera dicotómica y en singular. Asimismo, la ley obtiene una acentualidad negativa bajo estas adjudicaciones de sentido vistas desde un punto de vista ultraconservador $\mathrm{y}$ tradicionalista. Los elementos que predominan son los residuales en términos de Williams y la tópica central que se basa en los derechos sexuales y reproductivos de las mujeres refuerza la doxa en tanto sentido común que indica que no podemos ejercer soberanía sobre los mismos, aún con la 26.485 sancionada y promulgada. El contradestinario construido en todo este proceso periodístico es el feminismo y, también, los/as legisladores/as que aprobaron la norma pero que, además, están a favor del debate acerca de la legalización y despenalización del aborto. La misógina manifiesta obstruye toda posibilidad de otorgar algún sentido legalista a las construcciones periodísticas en un marco democrático y de derechos. En suma, la centralidad del sentido expresado es masculina, ellos dicen sobre el tema de la violencia contra las mujeres y, también, sobre los derechos sexuales y reproductivos, desde posiciones dominantes y de privilegio mientras que, son ellos quienes deslegitiman otras voces, principalmente, de mujeres, feministas que después de ardua lucha, consiguieron la sanción y promulgación de esta norma.

En síntesis, bajo el tratamiento periodístico realizado por La Nación sobre la ley en cuestión, el discurso construido sobre la norma y acerca de la problemática en sí, se orienta a alertar sobre el devenir de "la cultura de la muerte" si las mujeres ejercen sus derechos sexuales $y$ 
reproductivos. Resulta un contrasentido, dado que la principal causa de muerte evitable de mujeres en Argentina está dada por las condiciones clandestinas, violentas e inseguras de interrumpir un embarazo no deseado. La Nación busca clausurar la posibilidad de que las mujeres ejerzan un derecho tan elemental como poder decidir sobre el propio cuerpo. Al respecto, podemos decir que el medio refuerza la violencia femicida en términos de Marcela Lagarde, dado que mujeres, niñas y adolescentes mueren o se encuentran en grave peligro de muerte por cuestiones que atañen a su salud. El sentido expresado por el matutino encuentra suelo fértil en un orden hegemónico socio-cultural que legitima el trato cruel y sexista, pero también, clasista, racista y xenófobo.

\section{CONCLUSIONES}

En este trabajo hemos focalizado en los sentidos y discursos periodísticos que los dos diarios de alcance nacional más importantes de Argentina, Clarín y La Nación, construyeron sobre la ley 26885 que versa sobre el problema de la violencia contra las mujeres, el cual se presenta como urgente de tratar en el país y en el mundo dadas las vidas que se pierden casi a diario. Entendemos que dicha ley representó un hito importante en nuestro país tanto en lo relacionado con el Estado y sus políticas públicas como en los movimientos de mujeres, feministas, etc. Para poder comprender el tratamiento que la prensa realiza sobre la problemática, focalizamos aquí en esta norma ya que eso nos permite trazar ciertas líneas de sentido, importantes de vislumbrar, para poder reflexionar y proponer acciones en los medios.

Los medios de comunicación son actores concretos en las disputas ideológicas y de sentido social, por tanto, sus construcciones discursivas sobre la violencia contra las mujeres y los femicidios se vuelven especialmente importantes en la lucha por la erradicación del flagelo.

En concreto y teniendo en cuenta los hallazgos expuestos, se encontró que, fiel a su estilo legalista que apunta a una clase media argentina tradicional, universitaria, blanca, burguesa, trabajadora, el periódico Clarín optó por una posición políticamente correcta frente 
a la sanción de la ley 26.485 en el año 2009. También, teniendo como horizonte ese lector modelo fue construyendo sentido, aunque no de manera homogénea ni estática, sobre la ley y el tema violencia de género. Podemos inferir que el diario, integrante del multimedio más grande y poderoso del país, encontró "oportuno" tomar en su agenda periodística un tema sensible que le posibilitaría sumar en el refuerzo de un sentido común orientado a mantener sus intereses de clase y/o sector social. La doxa construida apunta a los valores neoliberales de la libertad entendida en términos individuales para lo cual se apela constantemente al enfoque legalista.

Por el lado de La Nación, se advierte que alude para eludir. Es decir, para este diario la ley en sí misma no es el foco ni el centro de su atención sino otros temas de interés con los que batalla: los derechos sexuales y reproductivos de las mujeres, el feminismo. Entonces, acerca de la sanción de la ley 26.485 de Prevención, Sanción y Erradicación de la violencia contra las mujeres, el posicionamiento fue de oposición. El sentido se orientó al contradestinatario
131

feminismo, como movimiento político por la igualdad de género y a las mujeres y sus avances en derechos fundamentales. Se apeló a un prodestinatario de valores tradicionales y conservadores, identificado con los preceptos más intransigentes de la iglesia católica, reforzando el mito de mujer $=$ madre $\mathrm{y}$ batallando contra la idea de que las mujeres puedan tomar libremente decisiones que atañen a su salud reproductiva.

En líneas generales, el tratamiento mediático que la misma recibió osciló entre la invisibilización y el desinterés, más aún, en comparación con la "explosión" mediática que tiene el tema de la violencia de género en la actualidad. Los medios, frecuentemente, la presentaron como una ley más, sin demasiadas especificaciones ni detenimientos en su articulado.

En Argentina, desde un punto de vista de género, la existencia de ley 26.485 es fundamental para visibilizar el problema de la violencia de género, expandir el sistema de nombres en tanto especifica tipos $y$ modalidades de violencia y para desplegar políticas públicas que contribuyan en la tarea de 
erradicar todo tipo de violencias contra las mujeres. En esto los medios tienen un importante rol y las políticas públicas que unen comunicación y género junto al accionar de las organizaciones sociales y la ciudadanía en general adquieren especial relevancia.

\section{REFERENCIAS BIBLIOGRÁFICAS}

Angenot, Marc (2010), El discurso social. Los límites de lo pensable y lo decible. Buenos Aires: Siglo XXI editores.

Barcaglione, Gabriela (2010), “Los Feminicidios en los medios de comunicación", en Sandra Chaher y Sonia Santoro (ed.) Las palabras tienen sexo IIHerramientas para un periodismo de género, Buenos Aires: Artemisa Comunicación Ediciones, 143-162.

Borrelli, Marcelo (2013), "Por una dictadura desarrollista: el diario Clarín durante los años de Videla y Martínez de Hoz (1976-1981)", en Los medios de comunicación como actores políticos: desafíos para el análisis actual en
132

sociedades latinoamericanas. Argentina: CAICYT CONICET.

Chaher, Sandra (2012), Derechos humanos, derechos de las mujeres $\mathrm{y}$ derecho a la comunicación. Documento de Cátedra. Diploma Superior de Comunicación y Género. Asociación civil Comunicar Igualdad y UNSAM.

De Moraes Denis (2013), Medios, poder y contrapoder: de la concentración monopólica a la democratización de la información/Denis de Moraes, Iganacio Ramonet, Pascual Serrano. Buenos Aires: Biblos.

Gramsci, Antonio (2011), Antología. Selección, traducción y notas de Manuel Sacristán. Buenos Aires: Siglo XXI.

Lagarde, Marcela (2012), "El derecho humano de las mujeres a una vida libre de violencia", en Marcela Lagarde, El feminismo en mi vida Hitos, claves y topías. México: Gobierno del Distrito Federal, Instituto de las Mujeres del Distrito Federal, 185-230. 
(2008), “Antropología, feminismo y política: Violencia feminicida y derechos humanos de las mujeres", en XI Congreso de Antropología: retos teóricos y nuevas prácticas.XI. Antropologia Kongresua: erronka teorikoak eta praktika berriak (14). Ankulegi Antropologia Elkartea, 209-240.

Ley $\mathrm{N}^{\circ}$ 26.485, "Violencia Contra la Mujer. Prevención, sanción y erradicación”. Boletín oficial del 14/04/09. Argentina. Versión electrónica, consultada el 23.02.2017, en http://novedades.filo.uba.ar/sites/novedad es.filo.uba.ar/files/6\%20ley-

$26485 \% 20$ violencia\%20contra\%20a\%201 a\%20mujer.pdf

Van Dijk, Teun (2003), Racismo y discurso de las élites. Barcelona: Gedisa. Verón, Eliseo (2004), Fragmentos de un tejido. Barcelona: Gedisa.

(1997), Semiosis de lo ideológico y del poder. La mediatización (Cursos y conferencias). Buenos Aires: Universidad de Buenos Aires.
(1987), “La palabra adversativa. Observaciones sobre la enunciación política", en El discurso político. Lenguajes y acontecimientos. Buenos Aires: Hachette. Versión electrónica, consultada el 20.02.2017, en http://semiotica2a.sociales.uba.ar/files/20 15/03/Veron-Adversativa.pdf

Voloshinov, Valentín (2009), El Marxismo y la filosofía del lenguaje. Buenos Aires: Godot.

Williams, Raymond (1980), Marxismo y Literatura. Barcelona: Península. 